\title{
U.S. GLOBEC Northeast Pacific Program: Overview
}

\author{
P. Ted Strub, Harold P. Batchelder \\ Oregon State University. Corvallis, Oregon USA
}

\author{
Thomas J. Weingartner \\ University of Alaska. Fairbanks, Alaska USA
}

\section{Introduction}

The bountiful natural resources of the Northeast Pacific (NEP) long sustained thriving populations of native peoples. The central importance of salmon, halibut, marine mammals, seabirds and other species to the cultural life of indigenous populations is beautifully represented in the legends and distinctive artwork of this region (Holm, 1965). Today, as human activities strongly affect terrestrial and aquatic ecosystems through harvesting of timber and fishery resources, water use practices, and habitat degradation in this region, the critical importance of understanding how these impacts might interact with further effects of global climate change is abundantly clear. The processes underlying the generally high productivity in the nearshore waters of the Northeast Pacific differ in the various subsystems and the effects of climate change can be expected to be manifested in distinctive ways in each (Batchelder et al., this issue; Weingartner et al., this issue). How these changes will affect overall levels of productivity in the Northeast Pacific is a critical question for GLOBEC researchers.

Changes in climate regimes on decadal time scales in the NEP are related to long-term variation in the intensity and position of the Aleutian Low and the Eastern North Pacific and Siberian High pressure systems (see Mantua et al., this issue). The Northeast Pacific is also strongly influenced by higher frequency variation related to El NiñoSouthern Oscillation (ENSO) events occurring on time-scales of 2-7 years. Strong variability in currents, water masses and species composition on both interannual and interdecadal scales makes the NEP a particularly interesting region of study. On ENSO time scales, some properties (coastal sea levels, temperature anomalies) covary in phase along the boundaries of the two major gyres (the Alaska and the California Current Systems), while the strengths of the boundary currents and water properties vary out of phase. The distributions of biological populations change over a wide range of trophic levels, due both to changes in advection and changes in water properties suitable for different species. On interdecadal time scales, the abundance of salmon populations and other commercially important species appear to covary out of phase in the two gyres (Figure 1). Thus the two linked ecosystems provide a natural laboratory in which to investigate mechanisms responsible for this variability.

Here, we provide a brief overview of U.S. GLOBEC studies in the Northeast Pacific to set the stage for more detailed summaries provided for programs in the California Current System (Batchelder et al., this issue) and the Coastal Gulf of Alaska (Weingartner et al., this issue)

\section{Program Development}

The status of the present GLOBEC NEP program is best understood by considering its history. Initial planning in the NEP program considered only the California Current System (CCS). The emphasis was on the interaction of mesoscale circulation features and population dynamics of zooplankton (including holozooplankton and the larvae of fish and benthic invertebrates). The central question concerned how these populations maintain their position in, or return to, environments favorable for survival, within a highly advective system.

Based on observations off Oregon in the 1970s (Huyer, 1983) and off northern California in the 1980s (Brink and Cowles, 1991), the circulation in the California Current System is expected to differ north and south of Cape Blanco (approximately $43^{\circ} \mathrm{N}$ ). North of the cape, the summer flow is approximately two-dimensional, with an alongshore upwelling jet that moves offshore and onshore in response to the wind. At Cape Blanco, the southward flowing jet separates from the coast and becomes a meandering free jet over the deep ocean offshore of the shelf (Barth et al., 2000). Between $35^{\circ}-43^{\circ} \mathrm{N}$, 


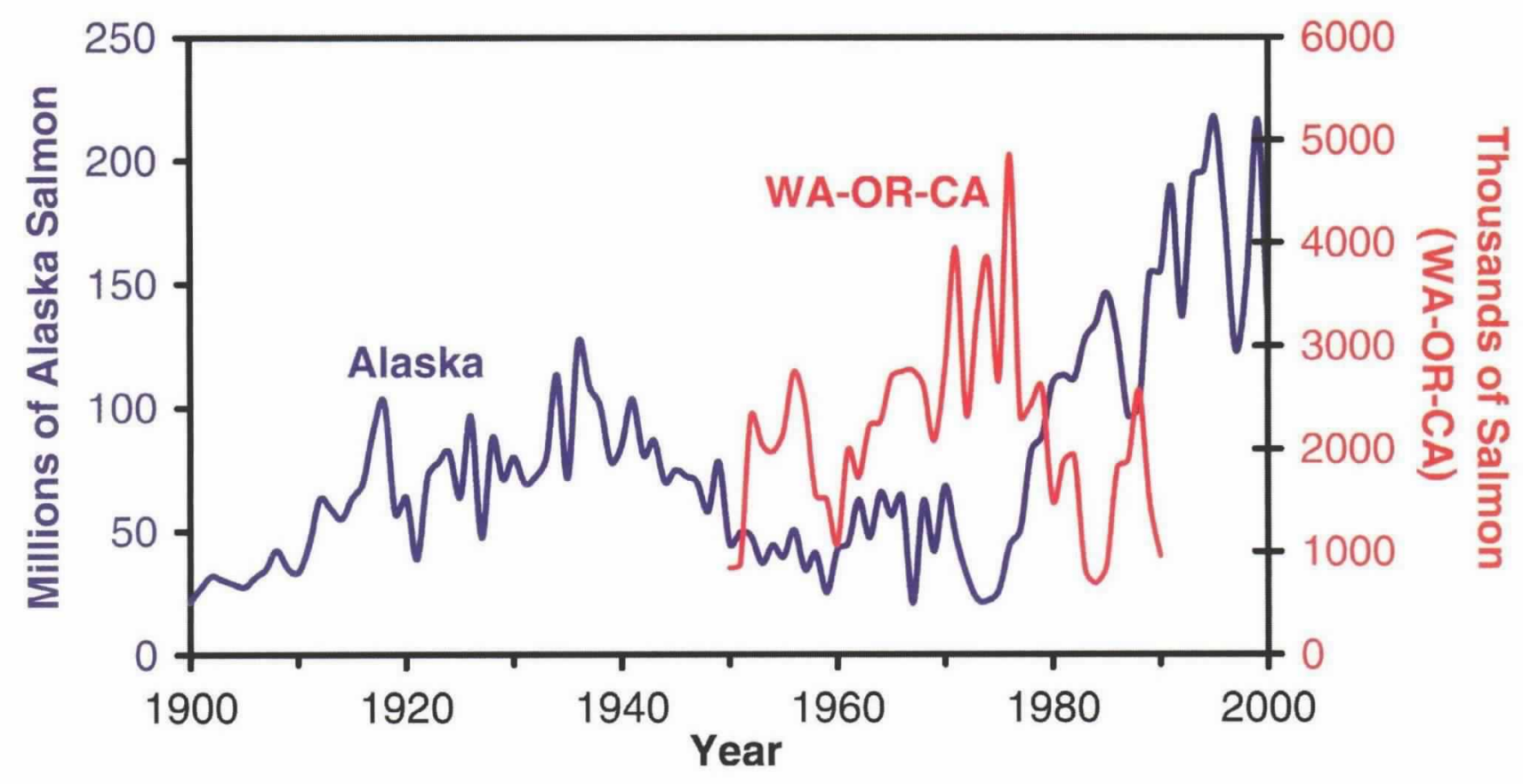

Figure 1. Commercial catch of salmon (all species combined) in the two regions of the Northeast Pacific. Fluctuations with high and low periods of 20-30 years are evident, as are shorter period fluctuations. Note that commercial salmon fishing in the PNW has been severely restricted since 1990, so data are absent after 1989.

the summer circulation patterns are more variable and dominated by three-dimensional mesoscale features (Strub and James, 2000). The initial CCS plans focused on comparisons of zooplankton population dynamics within these two distinct regions, in order to determine the interactions of the strong mesoscale variability in the region off northern California (U.S. GLOBEC, 1992, 1994). Both of these regions are also affected strongly by El Niño events, which are expected to occur sometime during a 5-7 year sampling program.

Separate plans were made for a U.S. GLOBEC program in the Coastal Gulf of Alaska (CGOA). The focus of the CGOA program was on the factors controlling the survival of salmon populations. It is hypothesized that the "oceanic survival of Pacific salmon is determined primarily by survival of juvenile salmon in coastal regions," and that this survival is affected by interannual and interdecadal climate variability (U.S. GLOBEC, 1996a). Thus, sampling during the juvenile salmon's first several months in the coastal ocean might explain much about patterns of growth, condition and potential causes of mortality. Both the availability of prey for salmon and predation on the juvenile salmon by fish, birds and mammals are topics of interest.

During the planning of the NEP program, there was a growing appreciation that many salmon populations in the CGOA appear to prosper when survival of species such as coho salmon is poor in the Pacific Northwest (Francis and Sibley, 1999; Hare et al., 1999; see Figure 1). Other species such as chinnok salmon do not appear to exhibit marked multidecadal fluctuation. Chelton and Davis (1982) originally proposed the hypothesis that the strength of the transports in the Alaska and California Currents vary out-of-phase on ENSO time scales (Figure 2). Analysis of historical zooplankton data in both systems by Brodeur et al. (1996) supported the hypothesis that zooplankton population sizes also vary out-of-phase on interannual time scales. The Chelton and Davis (1982) hypothesis was extended to interdecadal time scales (Hollowed and Wooster, 1995) to account for observed decadal shifts in the abundance of salmon and other marine fish populations in the Northeast Pacific (Hare et al., 1999; Andersen and Piatt, 1999). On both scales, the implication is either that these transports somehow control productivity, as observed off southern California (Chelton et al., 1982), or that the same atmospheric forcing that causes changes in the transports also directly affects the fish populations, for example through the interaction of turbulent surface mixing and stratification (Gargett, 1997). Examination of several basin-scale environmental indices show that the periodicity in salmon and other fish catch is at least partially correlated with physical changes in the large-scale North 


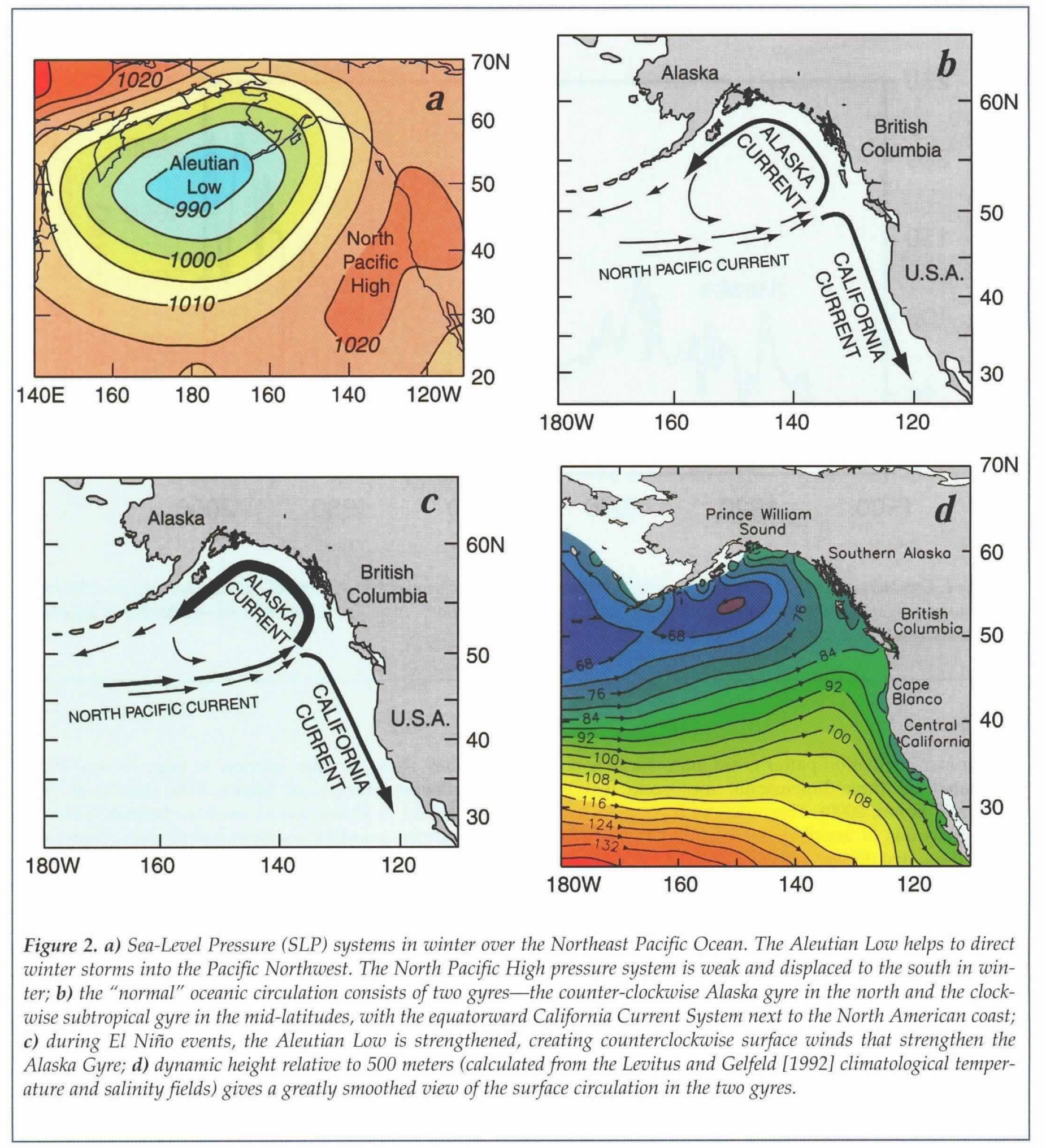

Pacific climate (in both the ocean and atmosphere; Mantua et al., 1997; Hare and Mantua, 2000; Hollowed et al., 2001). These changes in salmon production are also coherent with fluctuations on sardine populations in several regions of the north and south Pacific basins (Lluch-Belda et al., 1989), suggesting a large-scale underlying mechanism. With a time-scale of several decades, changes in atmospheric forcing and oceanic conditions during these alternating climate "regimes" are hypothesized to create connections between population fluctuations in the large-scale Pacific Ocean, including the CGOA and the CCS.

The recognition that the CCS and CGOA systems are linked on interannual and interdecadal scales provided the rationale to combine the two planning efforts and form the present Northeast Pacific program (U.S. 
GLOBEC, 1996b). The specific study sites are near Prince William Sound in the CGOA and off Oregon and northern California in the CCS. The program is designed to first identify biophysical interactions that affect zooplankton and salmon populations within each system. Comparisons between the two systems will then be used to identify the mechanisms responsible for fluctuations in overall ecosystem productivity and salmon abundance.

Target species in both systems include zooplankton, salmon, and their predators. In the CCS, the principal target species are copepods of the genus Calanus (C. pacificus and $C$. marshallae), the euphausiids Euphausia pacifica and Thysanoessa spinifera, and juvenile coho (Oncorhynchus kitsutch) and chinook (O. tshawytscha) salmon. The zooplankton selected for special emphasis are subarctic or transitional species common to both the CGOA and the CCS. Juvenile salmon were selected as target taxa because salmon growth and survival during their first summer at sea in coastal regions is sensitive to interdecadal and interannual alteration in ocean conditions (Fisher and Pearcy, 1988; Pearcy, 1992). Thus, changes in coastal ocean conditions and productivity should be expected to impact salmon survival and subsequent year-class strength. Although coho and chinook salmon are target fish species in the CCS, far-

ther north in the CGOA, where species such as pink and sockeye salmon dominate, pink salmon $(O$. gorbucsha) is the target fish species. The target zooplankton species in the CGOA include the copepods C. pacificus, C. marshallae, Neocalanus plumchris, and N. flemingeri and the euphausiids E. pacifica, T. spinifera, T. inermis, and $T$. raschii.

The underlying hypotheses of the NEP program are (U.S. GLOBEC, 1996b):

(1) Production regimes in the CGOA and CCS covary, and are coupled through atmospheric and ocean forcing;

(2) Spatial and temporal variability in mesoscale circulation constitutes the dominant physical forcing on zooplankton biomass, production, distribution, species interactions, retention and loss in coastal regions;

(3) Ocean survival of salmon is primarily determined by survival of the juveniles in coastal regions, and is affected by interannual and interdecadal changes in physical forcing and by changes in ecosystem food web dynamics.

\section{Research Approach}

The methods used to address the hypotheses above follow the GLOBEC strategy of inter-related retrospective analysis, modeling, process studies, observational programs and technological development (Fogarty et al., this issue). In the Northeast Pacific, GLOBEC observational programs include the Long-Term Observation Program (LTOP) in which key physical and biological variables are monitored along established transects in both the California Current and the Coastal Gulf of Alaska. In the CCS Program, a mesoscale observation program designed to provide three dimensional coverage encompassing the LTOP lines and to coincide with process study years is also underway. A similar program is under consideration for the coastal Gulf of Alaska for possible implementation in 2003.

GLOBEC studies in the Northeast Pacific were initiated in 1997 with Long-Term Observing Programs in both the CGOA and CCS. These pilot studies were implemented in response to emerging evidence that a strong El Niño event was developing. Retrospective studies and model development were initiated at the same time. The intensive process study phase of the project began in 2000 and 2001 in the CCS and the CGOA, respectively. The second intensive process study will occur in 2002 (CCS) and 2003 (CGOA), while ongoing LTOP sampling provides the context for the two more intensive periods of process studies at each site. A listing of measurements, instrumentation, and principal investigators for the NEP program can be found at http://globec.oce.orst.edu/group/nep.

The sites in both the CCS and CGOA were chosen to address the scientific hypotheses, while also making use of historical data sets and leveraging contemporary measurements from other programs. The region studied in the CCS extends from south of Cape Blanco (where mesoscale activity is expected to be more intense) to central Oregon off Newport (where the more two-dimensional system is observed). Initial results from the first intensive field year in the CCS are summarized by Batchelder et al. (this issue). In the CGOA, the primary measurements occur along a transect stretching southeast from Seward, covering the much broader shelf to the shelfbreak. Measurements are also made within Prince William Sound (PWS) and at locations where Alaska Coastal Current water enters and exits PWS (Weingartner et al., this issue).

In both of the NEP regions, the GLOBEC measurements will be augmented by both historical data and other contemporary programs. Historical hydrographic data off Oregon are available from a comprehensive 1960-1970 climatology (Huyer, 1977). Contemporary sampling in this region includes programs funded by NOPP (1999), CoOP (2001), and the Bonneville Power Administration (1998-2002). Similarly, the choice of the Seward transect as the CGOA GLOBEC site was based on the availability of historical hydrographic and 
mooring data from the same region (Johnson et al., 1988), as well as measurements made by the SEA, FOCI and CCCC programs (see the acronym list at the end of this article). Triennial NMFS surveys of groundfish occur in both regions and juvenile salmon are also being studied off southeast Alaska (including zooplankton and hydrographic data). In addition, there are ongoing Canadian studies on the continental shelf around Vancouver Island, connecting the two regions.

The timing of the LTOP and process study measurements in the NEP has been opportune. The initial LTOP time series captured the onset and development of the intense 1997-1998 El Niño and the rapid reversal to strong La Niña conditions in 1998 (Huyer et al., 2002). There is also speculation that a lower frequency regime shift occurred in 1998-1999. Whether or not a switch to a new regime has occurred, sampling in both systems has captured dramatic environmental changes. Preliminary analysis indicates that zooplankton species distributions, overall productivity and salmon survival all changed markedly in 1999 in the CCS (Batchelder et al., this issue).

Beside the rapid change in environmental conditions and populations during 1999, the other unifying theme that is emerging from the measurements in both regions is that the mesoscale circulation patterns are strongly influenced by the underlying topography and the coastline geometry. This provides a point of comparison with the U.S. GLOBEC measurements in the NW Atlantic, where topographic control of currents around Georges Bank is the central theme (Wiebe et al., this issue), and with recent measurements in the GLOBEC Southern Ocean program (Hofmann et al., this issue). Thus, we anticipate opportunities for comparisons between all U.S. GLOBEC study regions when these rich data sets are complete.

The GLOBEC NEP program is now at its halfway point. After the second intensive process-study years are completed in 2002-2003, an analysis and synthesis phase is expected to complete the program. The challenge, then, will be to turn these observations into understanding and to incorporate that understanding in biophysical ecosystem models of the NEP.

\section{List of Acronyms:}

CCCC: Carrying Capacity and Climate Change

CCS: California Current System

CGOA: Coastal Gulf of Alaska

CoOP: Coastal Ocean Processes

FOCI: Fisheries Oceanography Coordinated

Investigations

GLOBEC: Global Ocean Ecosystem Dynamics

Experiment

LTOP: Long-Term Observational Program

NEP: Northeast Pacific

NMFS: National Marine Fisheries Service
NOPP: National Ocean Partnership Program

PWS: Prince William Sound

SEA: Sound Ecosystem Assessment

\section{Acknowledgements}

The authors would like to thank Mike Fogarty for suggested text that improved the introduction and the many other GLOBEC principal investigators who provided comments on the original draft of this manuscript.

This U.S. GLOBEC contribution Number 231.

\section{References}

Andersen, P.J. and J.F. Piatt, 1999: Community reorganization in the Gulf of Alaska following a climate regime shift. Mar. Ecol. Prog. Ser., 189, 117-123.

Barth, J.A., S.D. Pierce and R.L. Smith, 2000: A separating coastal upwelling jet at Cape Blanco, Oregon and its connection to the California Current System. Deep-Sea Res. II, 47, 783-810.

Brink, K.H. and T.J. Cowles, 1991: The coastal transition zone program. J. Geophys. Res., 96, 637-647.

Brodeur, R.D., B.W. Frost, S.R. Hare, R.C. Francis, R.C. and W.J. Ingraham, Jr., 1996: Interannual variations in zooplankton biomass in the Gulf of Alaska, and covariation with California Current zooplankton biomass. CalCOFI Rep., 37, 80-99.

Chelton, D.B. and R.E. Davis, 1982: Monthly mean sealevel variability along the west coast of North America. J. Phys. Oceanogr., 12, 757-784.

Chelton, D.B., P.A. Bernal and J.A. McGowan, 1982: Large-scale interannual physical and biological interation in the California Current. J. Mar. Res., 40, 1095-1125.

Fisher, J.P. and W.G. Pearcy, 1988: Growth of juvenile coho salmon (Oncorhynchus kisutch) in the ocean off Oregon and Washington, USA, in years of differing coastal upwelling. Can. J. Fish. Aquat. Sci., 45, 1036-1044.

Francis, R.C. and T.H. Sibley, 1991: Climate change and fisheries: what are the real issues? NW Environ. J., 7, 295-307.

Gargett, A.E., 1997: The optimal stability 'window': A mechanism underlying decadal fluctuations in North Pacific salmon stocks. Fish. Oceanogr., 6, 109-117.

Hare, S.R. and N.J. Mantua, 2000: Empirical evidence for North Pacific regime shifts in 1977 and 1989. Prog. Oceanogr., 47, 103-145.

Hare, S.R., N.J. Mantua and R.C. Francis, 1999: Inverse production regimes: Alaskan and West Coast salmon. Fisheries, 24, 6-14.

Hollowed, A.B., S.R. Hare and W.S. Wooster, 2001: Pacific basin climate variability and patterns of Northeast Pacific marine fish production. Prog. Oceanogr., 49, 257-282.

Hollowed, A.B. and W.S. Wooster, 1995: Decadal-scale variations in the eastern subarctic Pacific: II 
Response of Northeast Pacific fish stocks. In: Climate Change and Northern Fish Populations. R.J. Beamish, ed., Canadian Special Publication of Fisheries and Aquatic Science, vol. 121, pp. 373-385.

Holm, B., 1965: Northwest Indian Art: an Analysis of Form. Univ. Washington Press.

Huyer, A, 1977: Seasonal variation in temperature, salinity, and density over the continental shelf off Oregon. Limnol. Oceanogr., 22, 442-453.

Huyer, A., 1983: Coastal upwelling in the California Current System. Prog. Oceanogr., 12, 259-284.

Huyer, A., R.L. Smith and J. Fleischbein, 2002: The coastal ocean off Oregon and northern California during the 1997-8 El Niño. Prog. Oceanogr., in press.

Johnson, W.R., T.C. Royer and J.L. Luick, 1988: On the seasonal variability of the Alaska Coastal Current. J. Geophys. Res., 93, 12423-12437.

Levitus, S. and R. Gelfeld, 1992: NODC Inventory of Physical Oceanographic Profiles. Key to Oceanography Records Documentation, No. 18. NODC, U.S. Gov. Printing Office, Washington, DC, 242 pp.

Lluch-Belda, D., R.J.M. Crawford, T. Kawasaki, A.D. MacCall, R.H. Parish, R.A. Swartzlose, and P.E.
Smith, 1989: World wide fluctuations of sardine and anchovy stocks: the regime problem. S. Afr. J. Mar. Sci., 8, 195-205.

Mantua, N., S. Hare, Y. Zhang, J. Wallace and R. Francis, 1997: A Pacific interdecadal climate oscillation with impacts on salmon production. Bull. Am. Met. Soc., 78, 1069-1079.

Pearcy, W.G., 1992: Ocean Ecology of North Pacific Salmonids. Washington Sea Grant., 179 pp.

Strub, P.T. and C. James, 2000: Altimeter-derived variability of surface velocities in the California Current System: 2. Seasonal circulation and eddy statistics. Deep-Sea Res. II, 47, 831-870.

U.S. GLOBEC, 1992: Eastern Boundary Current Program: Report on Climate Change and the California Current Ecosystem. U.S. GLOBEC Report 7, 99 pp.

U.S. GLOBEC, 1994: Eastern Boundary Current Program, A Science Plan for the California Current. U.S. GLOBEC Report 11, 134 pp.

U.S. GLOBEC, 1996a: North Pacific Climate Change and Carrying Capacity (CCCC) Science Plan. U.S. GLOBEC Report 16, 44 pp.

U.S. GLOBEC, 1996b: U.S. GLOBEC Northeast Pacific Implementation Plan. U.S. GLOBEC Report 17, 60 pp.

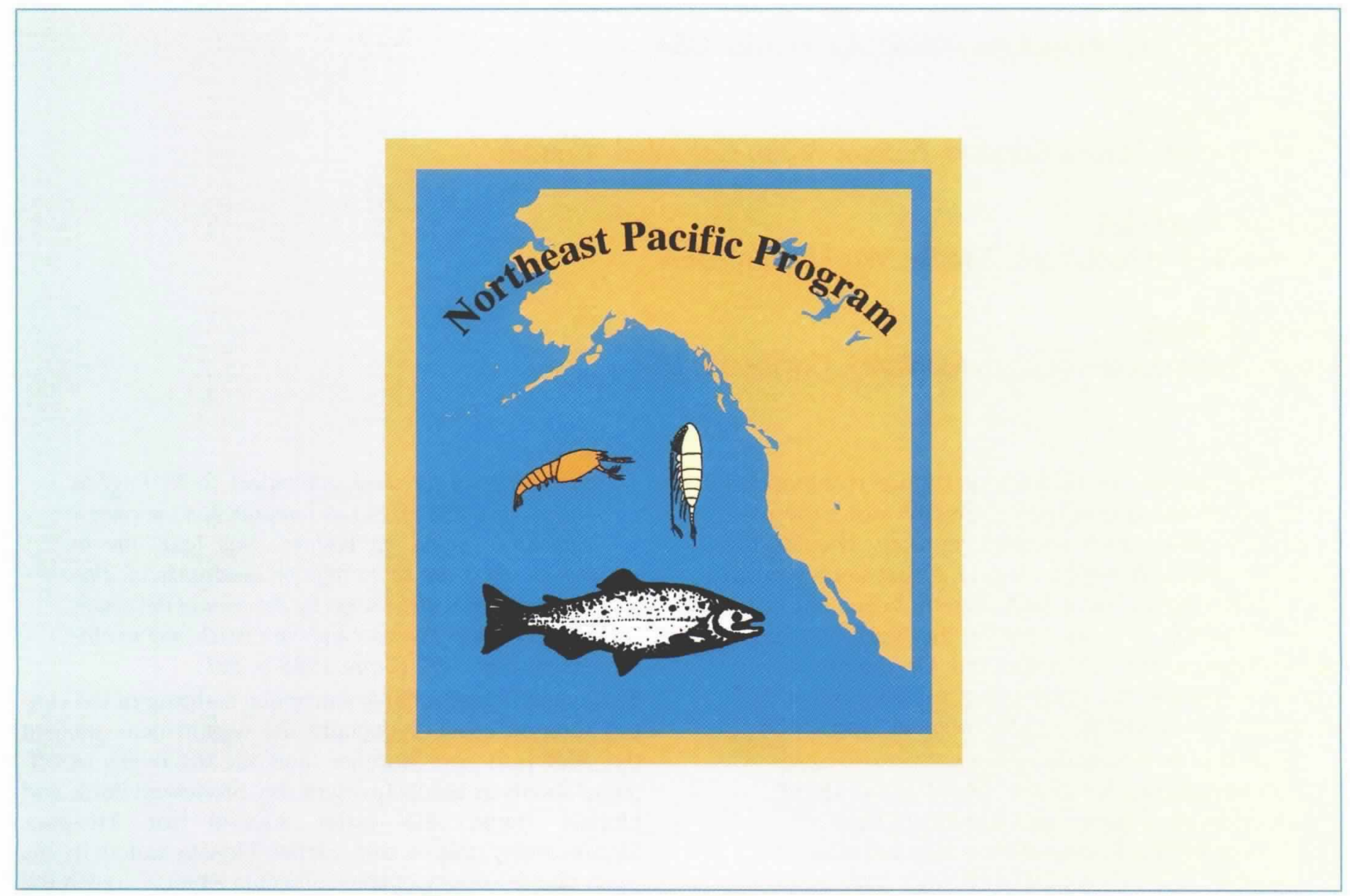

